\title{
Mechanism for the Peroxide-Initiated Crosslinking of Polyethylene in the Presence of 2,4-Diphenyl-4-methyl-1-pentene
}

\author{
Shuji Suyama, ${ }^{*}$ Hideyo Ishigaki, Yasumasa Watanabe, \\ and Tomoyuki NaKamura \\ Fine Chemicals \& Polymers Research Laboratory, NOF Corporation,
Taketoyo-cho, Chita-gun, Aichi 470-23, Japan
}

(Received October 17, 1994)

\begin{abstract}
The model reaction for the crosslinking of polyethylene (PE) in the presence of 2,4-diphenyl-4-methyl-1-pentene ( $\alpha$-methylstyrene dimer: MSD) was carried out using $n$-undecane instead of PE and using di-t-butyl peroxide as an initiator at $140^{\circ} \mathrm{C}$. Undecyl radicals produced by hydrogen abstraction by peroxide radicals from $n$-undecane effectively added to the double bond of MSD to form adduct radicals, which then underwent fragmentation to give olefins and cumyl radicals. The concentration of olefins initially increased, but decreased through a maximum. It was found that the olefins are intermediate products which further react with undecyl radicals, resulting in the formation of compounds with two or three undecyl groups.
\end{abstract}

KEY WORDS Crosslinking / Polyethylene / Mechanism / Coagent / $\alpha$-Methylstyrene Dimer /

The crosslinking of polyethylene (PE) is conveniently achieved by the use of organic peroxides as crosslinking agents. The efficiency of the peroxide-initiated crosslinking can be greatly increased by the addition of coagents (crosslinking activators) such as triallyl cyanurate, triallyl isocyanurate, quinone dioxime, diallyl phthalate, ethylene glycol dimethacrylate, trimethylolpropane trimethacrylate, $N$, $N^{\prime}$-m-phenylene bismaleimide, 1,2-polybutadiene and so on. ${ }^{1-5}$

In addition to increasing the crosslinking efficiency, it is also important to prevent premature crosslinking which may occur during the pre-crosslinking process. The premature crosslinking is commonly referred to as scorch. It was reported that nitrites, ${ }^{6}$ 2-mercaptobenzothiazole, ${ }^{7}$ and hydroquinones ${ }^{8}$ act as effective scorch inhibitors for PE crosslinking.

Recently, we reported that 2,4-diphenyl4-methyl-1-pentene $(\alpha$-methylstyrene dimer: MSD) is quite a useful coagent for PE

\footnotetext{
* To whom all correspondence should be addressed.
}

crosslinking. ${ }^{9}$ That is, MSD prevented scorch and also increased the crosslinking efficiency. This result is quite strange since prevention of scorch generally causes a decrease of the crosslinking efficiency if the action mechanism of MSD remains unchanged during the crosslinking. Thus, it was suggested that the action mechanism of MSD would change as the crosslinking reaction proceeds.

To elucidate the crosslinking mechanism of PE in the presence of MSD, we carried out a model reaction using a simple alkane, $n$ undecane, instead of PE. In this paper, we report the results of the detailed products analysis for the model reaction and present a reasonable crosslinking mechanism.

\section{EXPERIMENTAL}

\section{Measurements}

GLC analysis was performed with a Shimadzu GC-9A gas chromatograph with a flame 
ionization detector using a $15 \mathrm{~m}$ fused silica capillary column $(0.53 \mathrm{~mm}$ in diameter $)$ coated with silicone OV-1. A Shimadzu Chromatopac C-R6A integrator was used for quantitative analysis. Mass spectra were obtained on a JEOL JMS-DX300 mass spectrometer under electron impact conditions.

\section{Materials}

2,4-Diphenyl-4-methyl-1-pentene (MSD) and di- $t$-butyl peroxide (DTBP) were received commercially (NOF Corporation). The purities of MSD and DTBP were $95 \%$ and $99 \%$, respectively. 2,4-diphenyl-4-methyl-2-pentene (4\%) and 1,1,3-trimethyl-3-phenylindane (1\%) were included in MSD as isomers. These isomers were inactive under the present reaction conditions.

\section{Reaction Procedure}

Typically, a $2 \mathrm{ml}$ of $n$-undecane solution containing $0.2 \mathrm{M}$ of DTBP and $0.1 \mathrm{M}$ of MSD was placed in a glass ampoule. The ampoule was purged with nitrogen, sealed, and immersed in a constant temperature bath regulated at $140^{\circ} \mathrm{C}$. After the reaction for a given time, the reaction products were analyzed by GLC and GC-MS in comparison with authentic samples.

\section{RESULTS AND DISCUSSION}

\section{Initial Reaction}

We carried out a free-radical reaction initiated by DTBP in $n$-undecane in the presence of MSD at $140^{\circ} \mathrm{C}$ under nitrogen. The reaction products after one hour were analyzed by GLC and GC-MS using authentic samples (Table I). The conversions of DTBP and MSD were $19 \%$ and $50 \%$, respectively. Here, the conversion of MSD denotes the conversion of 2,4-diphenyl-4-methyl-1-pentene which is a major component $(95 \%)$ of MSD. Biscumyl, cumene, $\alpha$-methylstyrene, and the coupling products of undecyl radicals and cumyl radicals (2) were confirmed as products having the
Table I. Products of free-radical reaction initiated by $\mathrm{DTBP}$ in $n$-undecane in the presence of $\mathrm{MSD}$ at $140^{\circ} \mathrm{C}^{\mathrm{a}}$

\begin{tabular}{cc}
\hline Product & Yield $/ \%$ \\
\hline (A) Products with the cumyl fragment \\
{$\left[\mathrm{PhC}\left(\mathrm{CH}_{3}\right)-\right]_{2}$} & $74^{\mathrm{c}}$ \\
$\mathrm{PhCH}\left(\mathrm{CH}_{3}\right)_{2}$ & 11 \\
$\mathrm{PhC}\left(\mathrm{CH}_{3}\right)=\mathrm{CH}_{2}$ & 11 \\
$\mathrm{PhC}\left(\mathrm{CH}_{3}\right)_{2}-\mathrm{R}(2)$ & 5 \\
$($ B) Products with the 2-phenylallyl fragment \\
$\mathrm{CH}_{2}=\mathrm{C}-\mathrm{CH}_{2}-\mathrm{R}^{\mathrm{d}}(\mathbf{1})$ & 94 \\
Ph &
\end{tabular}

a DTBP concn, 0.2 M; MSD concn, 0.1 M; Reaction time, $1 \mathrm{~h}$; DTBP conversion, 19\%; MSD conversion, $50 \%$. ${ }^{\mathrm{b}} \mathrm{Mol} \%$ yield based on MSD reacted. ${ }^{\mathrm{c}}$ Yield of cumyl group. ${ }^{\mathrm{d}} \mathrm{R}$ denotes undecyl groups.

cumyl fragment of MSD. Olefins (1) with undecyl groups were also confirmed as products having the 2-phenylallyl fragment of MSD. The mass spectra of 1 showed the parent peak $\left(\mathrm{M}^{+}\right)$of 272 . The recovery of the cumyl and 2-phenylallyl fragment was pretty high $(>90 \%)$. These results clearly demonstrate that $\mathrm{C}-\mathrm{C}$ bond fragmentation between the cumyl group and the 2-phenylallyl group is induced by the attack of undecyl radicals onto MSD.

Recently, we reported that MSD undergoes chain transfer through a free radical additionfragmentation reaction in styrene polymerization. ${ }^{10}$ That is, propagating polymer radicals add to the double bond of MSD to give intermediate adduct radicals (eq 1), and then the adduct radicals undergo fragmentation to expel cumyl radicals (eq 2). The driving force of the addition-fragmentation reaction was rationalized in terms of the activation towards radical addition of the double bond by phenyl group and the presence of the weak $\mathrm{C}-\mathrm{C}$ bond in a $\beta$-position to the adduct radical that can undergo fragmentation.

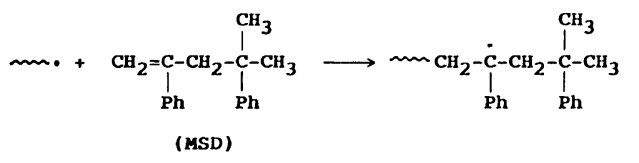




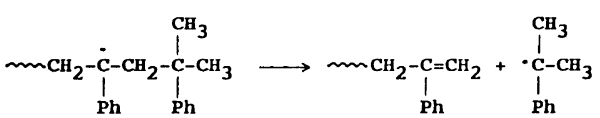

Thus, the reaction products listed in Table I are reasonably explained by the following equations, including the addition-fragmentation reaction between MSD and undecyl radicals.

$$
\begin{aligned}
& \mathrm{t}-\mathrm{BuOOBu}-\mathrm{t} \longrightarrow 2 \mathrm{t}-\mathrm{BuO}^{\circ} \\
& \text { (DTBP) } \\
& \mathrm{t}-\mathrm{BuO} \cdot \stackrel{\stackrel{\mathrm{O}}{\|}}{\mathrm{CH}} \mathrm{CH}_{3}-\mathrm{C}-\mathrm{CH}_{3}+\mathrm{CH}_{3} \cdot \\
& t-\mathrm{BuO}^{-}+\mathrm{RH} \longrightarrow \mathrm{t}-\mathrm{BuOH}+\mathrm{R}^{\cdot} \\
& \mathrm{CH}_{3}{ }^{-}+\mathrm{RH} \longrightarrow \mathrm{CH}_{4}+\mathrm{R}^{-} \\
& \mathrm{R}^{\cdot}+\mathrm{MSD} \longrightarrow \mathrm{R}-\mathrm{CH}_{2}-\left.\underset{\mathrm{Ph}}{-\mathrm{C}-\mathrm{CH}_{2}}\right|_{\mathrm{Ph}} ^{\stackrel{\mathrm{C}}{\mathrm{C}}-\mathrm{CH}_{3}}
\end{aligned}
$$

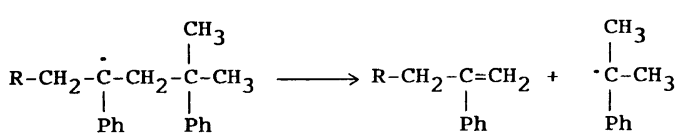

$$
\begin{aligned}
& \text { (1) }
\end{aligned}
$$

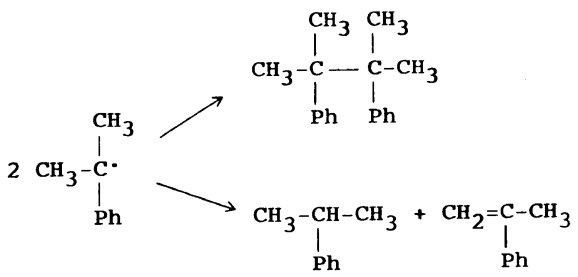

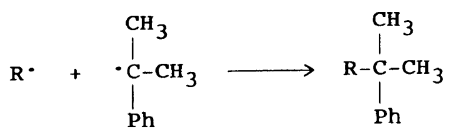

Here, $\mathrm{RH}$ and $\mathrm{R}^{\circ}$ denote $n$-undecane and undecyl radicals with various isomers, respectively. The $\mathrm{O}-\mathrm{O}$ bond homolysis of DTBP gives $t$ - $\mathrm{BuO}^{\circ}$ (eq 3), some of which then undergo fragmentation to produce $\mathrm{CH}_{3}{ }^{\circ}$ and acetone (eq 4). Hydrogen abstraction by $t-\mathrm{BuO}^{\circ}$ and $\mathrm{CH}_{3}{ }^{\circ}$ from $\mathrm{RH}$ produces $\mathrm{R}^{\cdot}$ (eq 5 and 6 ). The addition of $\mathbf{R}^{\cdot}$ to MSD gives intermediate adduct radicals (eq 7), which then undergo fragmentation to produce olefins (1) and cumyl radicals (eq 8). The expelled cumyl radicals mainly undergoes self-combination to give biscumyl (eq 9a). Alternative disproportionation of cumyl radicals gives cumene and $\alpha$-methylstyrene (eq $9 \mathrm{~b}$ ). The coupling of the cumyl radical and $\mathrm{R}^{\circ}$ produces 2 (eq 10 ).

In the absence of MSD, the major products were the dehydrodimers of $\mathrm{RH}$, i.e., $\mathrm{R}-\mathrm{R}$ $(0.032 \mathrm{M})$, which correspond to crosslinked products. However, we could not detect any $\mathrm{R}-\mathrm{R}$ in the presence of MSD $(<0.0005 \mathrm{M})$. This clearly demonstrates that the addition of $\mathrm{R}^{\cdot}$ to MSD (eq 7) is much faster than the bimolecular self-reactions of $\mathrm{R}^{*}$ (combination and disproprotionation) (eq 11).

$$
\mathrm{R}^{\cdot}+\mathrm{R}^{\cdot} \stackrel{2 \mathrm{k}_{\mathrm{t}}}{\longrightarrow} \text { molecular products }
$$

The faster addition reaction seems to be quite reasonable from the following kinetic analysis. The rate for the bimolecular self-reactions of $\mathrm{R}^{\bullet}\left(r_{\mathrm{t}}\right)$ is expressed as $2 k_{\mathrm{t}}\left[\mathrm{R}^{\circ}\right]^{2}$. It is known that the rate constants of $2 k_{\mathrm{t}}$ for simple alkyl radicals are approximately $2 \times 10^{9} \mathrm{M}^{-1} \mathrm{~s}^{-1} .^{11}$ The concentration of $\mathrm{R}^{\cdot}$ depends on the decomposition rate of DTBP. It was reported that the decomposition rate constant of DTBP $\left(k_{\mathrm{d}}\right)$ is $6.40 \times 10^{-5} \mathrm{~s}^{-1}$ in decane at $140^{\circ} \mathrm{C} .{ }^{12}$ Using the $k_{\mathrm{d}}$ value and applying the steady state assumption to $\mathbf{R}^{*}$, the concentration of $\mathrm{R}^{\circ}$ under the present reaction conditions is estimated as about $1.1 \times 10^{-7} \mathrm{M}$ when DTBP concentration is $0.2 \mathrm{M}$. Thus, $r_{\mathrm{t}}$ is estimated as about $2.4 \times 10^{-5} \mathrm{Ms}^{-1}$. On the other hand, the rate for the addition of $\mathrm{R}^{\circ}$ to $\operatorname{MSD}\left(r_{\mathrm{a}}\right)$ is expressed as $k_{\mathrm{a}}\left[\mathrm{R}^{\circ}\right][\mathrm{MSD}]$, where $k_{\mathrm{a}}$ denotes the addition rate constant. Although the value of $k_{\mathrm{a}}$ is not known, it is assumed to be about the same as that for the rate constant for 
addition of 5-hexenyl radical to styrene $\left(k_{\mathrm{a}}{ }^{\prime}\right)$ reported by Citterio et al. ${ }^{13}$ They presented Arrhenius parameters of $E_{\mathrm{a}}=4.88 \mathrm{kcal} \mathrm{mol}^{-1}$ and $\log \left(A /\left(\mathrm{M}^{-1} \mathrm{~s}^{-1}\right)\right)=8.33$ for the addition reaction. Using these parameters, $k_{\mathrm{a}}{ }^{\prime}$ at $140^{\circ} \mathrm{C}$ is calculated to be $5.5 \times 10^{5} \mathrm{M}^{-1} \mathrm{~s}^{-1}$. Thus, the value of $r_{\mathrm{a}}$ is estimated as $6.1 \times 10^{-3} \mathrm{Ms}^{-1}$ when MSD concentration is $0.1 \mathrm{M}$. From the comparison between $r_{\mathrm{t}}$ and $r_{\mathrm{a}}$, we can roughly estimate the rate for addition of $\mathrm{R}^{\cdot}$ to MSD to be about 250 times that for the bimolecular self-reactions of $R^{*}$. This kinetic analysis is consistent with the experimental result that $\mathrm{R}^{\circ}$ predominantly added to MSD.

For the crosslinking of $\mathrm{PE}, \mathrm{R}^{\circ}$ can be considered to be $\mathrm{PE}$ radical $\left(\mathrm{P}^{*}\right)$. The present products analysis in the initial stage clearly indicates that the formation of $\mathrm{P}-\mathrm{P}$ would be greatly suppressed by MSD when PE crosslinking is carried out in the presence of MSD. This is consistent with the previous result that scorch is effectively prevented by the presence of MSD for the crosslinking of PE. ${ }^{9}$

\section{Crosslinking Mechanism}

The concentration changes of MSD and olefins (1) are shown in Figure 1. Interestingly, the concentration of $\mathbf{1}$ sharply increased at first, but reached a maximum at around $2 \mathrm{~h}$, and then decreased. This clearly demonstrates that $\mathbf{1}$ is a reactive intermediate. Since $\mathbf{1}$ has the double bond activated by the phenyl group as well as MSD, it is easily predictable that $\mathrm{R}^{\circ}$ add to the double bond of $\mathbf{1}$ to give adduct radicals (3) (eq 12).

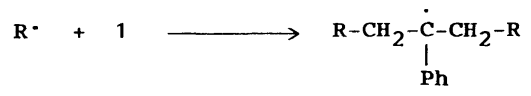

(3)

With decreasing 1 , several peaks appeared in the region of longer retention times than 1 on the GLC chart. These peaks were divided into two groups which greatly differ from one another in retention times. The mass spectra of the former group showed the parent peak $\left(\mathrm{M}^{+}\right)$of 426 or 428 , and those of the latter

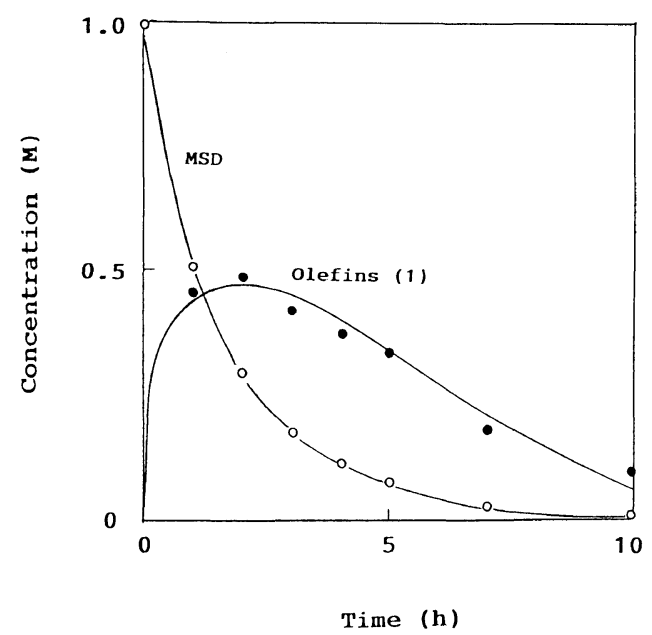

Figure 1. Concentration changes of MSD and 1 during the free-radical reaction initiated by DTBP in $n$-undecane in the presence of $\mathrm{MSD}$ at $140^{\circ} \mathrm{C}$ : (O), MSD; (O), 1; DTBP, $0.2 \mathrm{M}$.

showed $\mathrm{M}^{+}$of 582. From these parent peaks and fragment peaks, it was found that the former group consists of the compounds (4) and (5) with two $R$ groups and the latter consists of the compound (6) with three $R$ groups. The formation of these compounds with two or three $\mathrm{R}$ groups is explained by the following equations.

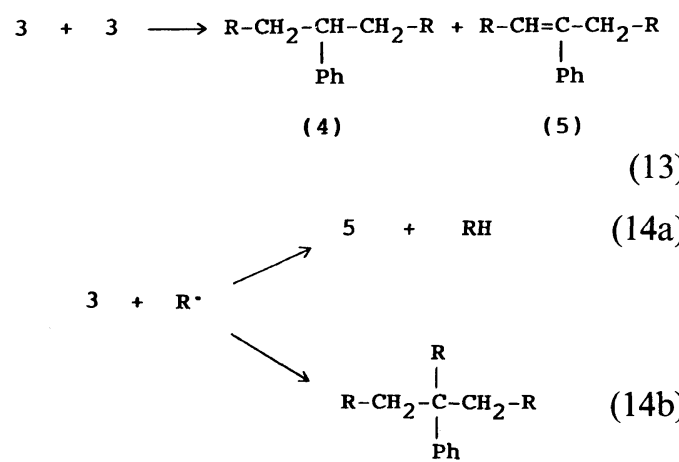

(6)

The disproportionation reaction of 3 results in the formation of 4 and 5 (eq 13). Also, the disproportionation reaction of 3 and $R^{\circ}$ leads to the formation of 5 (eq 14a). The combination reaction of 3 and $\mathbf{R}^{\circ}$ leads to the formation of 


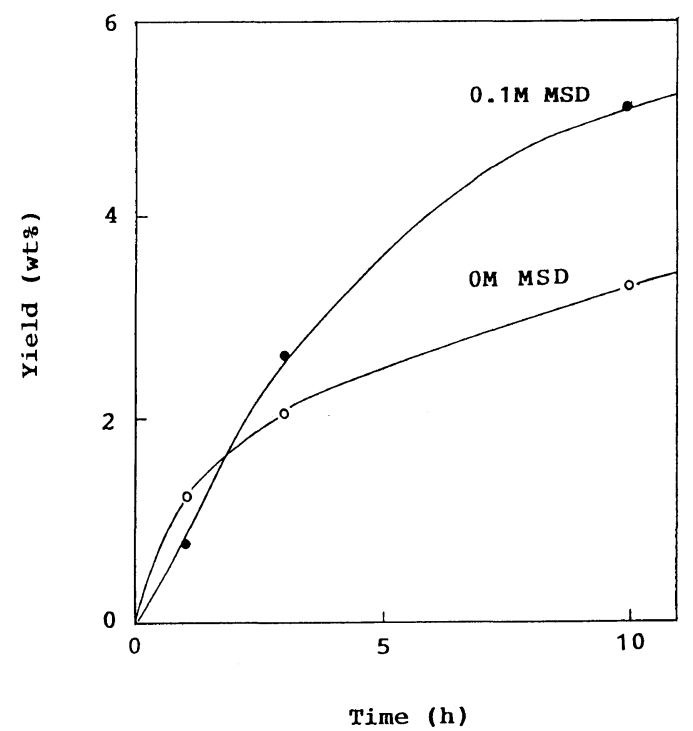

Figure 2. Yields of compounds with two or three $\mathbf{R}$ groups produced in free-radical reaction initiated by DTBP in $n$-undecane at $140^{\circ} \mathrm{C}:(\bigcirc), 0 \mathrm{M} \mathrm{MSD} ;(\bigcirc), 0.1 \mathrm{M} \mathrm{MSD}$; DTBP, $0.2 \mathrm{M}$.

\section{6 (eq 14b).}

Each yield of 4, 5, and 6 could not be determined by GLC due to their broad peaks. So, after the reaction for given times, we removed the low boiling materials by evaporation and measured the total weight of compounds 4, 5, and 6 . Similarly, in the absence of MSD, the yield of $R-R$ was determined. The results are shown in Figure 2. Evidently, in the initial stage, the yield of compounds with two or three R groups in the presence of MSD was lower than that in the absence of MSD, but in the later stage the situation became reversed. This result is consistent with the previous result obtained in the crosslinking of PE in the presence of MSD. ${ }^{9}$ That is, when MSD was added, torque increased more mildly at $140^{\circ} \mathrm{C}$ (initial stage), but increased more rapidly and reached a higher maximum value at $180^{\circ} \mathrm{C}$.
Thus, the production of highly cross-linked polymers in PE crosslinking in the presence of MSD is ascribed to the formation of the reactive olefinic intermediates which can further react with polymer radicals.

In conclusion, the crosslinking of PE in the presence of MSD proceeds in two stages. In the first stage, addition-fragmentation reaction occurs between MSD and polymer radicals to produce reactive olefins (eq 15). And then, the olefins react with polymer radicals to produce crosslinked polymers (eq 16).

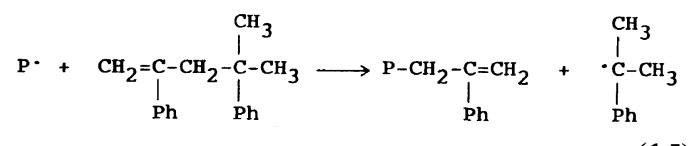

$$
\mathrm{P} \cdot+\mathrm{CH}_{2}=\underset{\mathrm{Ph}}{\mathrm{C}-\mathrm{CH}_{2}-\mathrm{P}} \longrightarrow \mathrm{P}-\mathrm{CH}_{2}-\left.\right|_{\mathrm{Ph}} ^{\dot{\mathrm{C}}-\mathrm{CH}_{2}-\mathrm{P}} \rightarrow \underset{\text { Polymers }}{\text { Crosslinked }}
$$

\section{REFERENCES}

1. A. E. Robinson, J. V. Marra, and L. O. Amberg, Ind. Eng. Chem. Prod. Res. Dev., 1, 78 (1962).

2. L. P. Lenas, Ind. Eng. Chem. Prod. Res. Dev., 2, 202 (1963).

3. P. O. Tawney, W. J. Wenisch, S. Van Der Burg, and D. I. Relyea, J. Appl. Polym. Sci., 8, 2281 (1964).

4. R. E. Drake, Elastomerics, 114, 28 (1982).

5. W. C. Endstra, Kautsch. Gummi, Kunstst., 43, 790 (1990).

6. H. K. Latourette and E. R. Gilmont, U. S. Patent 3202648 (Aug. 24, 1965).

7. H. R. Larsen, U. S. Patent 3335124 (Aug. 8, 1967).

8. J. Groepper, Gummi Fasern Kunstst., 47, 83 (1994).

9. S. Suyama, H. Ishigaki, Y. Watanabe, and T. Nakamura, Polym. J., in press.

10. Y. Watanabe, H. Ishigaki, H. Okada, and S. Suyama, Chem. Lett., 1089 (1993).

11. K. U. Ingold, "Free Radicals," Vol. I, J. K. Kochi, Ed., John Wiley \& Sons, New York, 1973, Chapter 2.

12. T. Yamamoto, Y. Nakashio, H. Onishi, and M. Hirota, Nippon Kagaku Kaishi, 2296 (1985).

13. A. Citterio, A. Arnoldi, and F. Minisci, J. Org. Chem., 44, 2674 (1979). 